\title{
Possible Spatial Extent of Ionospheric GPS-TEC and NmF2 Anomalies Related to the 1999 Chi-Chi and Chia-Yi Earthquakes in Taiwan
}

\author{
Masahide Nishihashi ${ }^{1}$, Katsumi Hattori ${ }^{2,}{ }^{*}$, Hau-Kun Jhuang ${ }^{3}$, and Jann-Yenq Liu ${ }^{3,4}$ \\ ${ }^{1}$ Graduate School of Science and Technology, Chiba University, Chiba, Japan \\ ${ }^{2}$ Graduate School of Science, Chiba University, Chiba, Japan \\ ${ }^{3}$ Institute of Space Science, National Central University, Jhongli, Taiwan, ROC \\ ${ }^{4}$ Center for Space and Remote Sensing Research, National Central University, Jhongli, Taiwan, ROC
}

Received 17 October 2008, accepted 22 January 2009

\begin{abstract}
Scientists analyzed temporal variations of local data recorded in Taiwan and reported anomalous reductions in the ionospheric total electron content (TEC) on days 4 and 3 before (17 and 18 September) the Chi-Chi earthquake $\left(\mathrm{M}_{\mathrm{w}}\right.$ 7.6, $M_{L}$ 7.3), and days 3 and 1 prior to (19 and 21 October) the Chia-Yi earthquake $\left(M_{L} 6.4\right)$ in Taiwan. In this paper, we propose a spatial analysis which compares the data recorded inside and outside of the earthquake area around Taiwan to discriminate whether the anomalies are local (earthquake related) or global (non-earthquake related) phenomena. Results suggest that the anomalies appearing day 3 before the Chi-Chi earthquake, and days 3 and 1 before the Chia-Yi earthquake are local (earthquake related) phenomena and the anomaly appearing on 17 September 1999 (day 4 before) might be the result of both global phenomena (i.e., a geomagnetic storm) and the local effect of the Chi-Chi earthquake.
\end{abstract}

Key words: Total Electron Content (TEC), NmF2, Anomalous reduction, Spatial analysis, The 1999 Chi-Chi and Chia-Yi earthquakes Citation: Nishihashi, M., K. Hattori, H. K. Jhuang, and J. Y. Liu, 2009: Possible spatial extent of ionospheric GPS-TEC and NmF2 anomalies related to the 1999 Chi-Chi and Chia-Yi earthquakes in Taiwan. Terr. Atmos. Ocean. Sci., 20, 779-789, doi: 10.3319/TAO.2009.01.22.01(T)

\section{INTRODUCTION}

Many anomalous electromagnetic phenomena possibly associated with large earthquakes have been reported (e.g., Hayakawa and Fujinawa 1994; Hayakawa 1999; Hayakawa and Molchanov 2002; Pulinets and Boyarchuk 2004). Ionospheric anomalies before large earthquakes were reported first in the beginning of the 1970s (Datchenko et al. 1972; Birfeld 1974; Nestorov 1979). Scientists (Pulinets et al. 1994; Pulinets 1998; Liu et al. 2000, 2006; Chuo et al. 2001, 2002) observed that the ionospheric plasma frequency (or corresponding electron density) decreased a few days before some large earthquakes occurred. Ionosondes have been the most popular instruments for probing the ionospheric electron density for more than seven decades (Hunscucker 1991). They provide excellent opportunities for studying pre-earthquake ionospheric anomalies. Gokhberg et al. (1989) revealed the existence of anomalies of the critical/plasma fre-

\footnotetext{
* Corresponding author

E-mail: hattori@earth.s.chiba-u.ac.jp
}

quency at the ionospheric F2-peak (foF2) a few days before several earthquakes. Currently, there are more than 200 ionosondes available worldwide; however, only a fraction of them is routinely operated. Therefore, spatial and temporal coverage of ionosonde observations are limited and difficult to use systematically for correlation with seismic activities. Moreover, because of the use of median and high frequencies (MF and HF) of $1-20 \mathrm{MHz}$, ionosondes often suffer from short-wave fadeout and in turn data gaps (Davies 1990).

On the other hand, due to developments in space technology, today there are thousands of ground-based receivers of the global positioning system (GPS) deployed to monitor the Earth's surface deformation rates (see the papers listed in Calais and Amarjargal 2000). Owing to the use of two ultra-high frequency (UHF, $f_{1}=1575.42 \mathrm{MHz}$ and $f_{2}=$ 1227.60 MHz) waves, GPS signals are generally free from short-wave fadeouts. Besides the Earth's surface deformation observations, the same network of GPS receivers can 
also be used to simultaneously and continuously monitor the ionospheric total electron content (TEC) (e.g., Sardon et al. 1994; Leick 1995; Liu et al. 1996). Researchers have reported anomalous reductions in GPS-TEC (e.g., Liu et al. 2001, 2004a) and/or foF2 (Liu et al. 2000, 2006; Chuo et al. 2001, 2002) that appeared within $1-5$ days prior to $M \geq 6.0$ earthquakes in Taiwan. Liu et al. (2004b) reported the statistical result that the GPS-TEC and foF2 decreased before 144 $M \geq 5.0$ earthquakes in Taiwan during 1997 - 1999. Moreover, Chen et al. (2004) demonstrated the statistical significance of observed foF 2 anomalies within 1 - 5 days prior to $M \geq 5.0$ earthquakes being related to such earthquakes in the Taiwan area for the period 1994 - 1999. Liu et al. (2006) defined the criteria for detecting pre-seismic events in the ionosphere and then applied those criteria with foF 2 and $184 \mathrm{M} \geq 5.0$ earthquakes in Taiwan between 1994 and 1999. Their study showed both positive and negative anomalies but that only the negative ones yielded statistical significance. They found, after removing geomagnetic storm effects, that ionospheric foF 2 significantly decreased during the afternoon period 1 - 5 days before the earthquakes. Based on the statistical results, scientists (Liu et al. 2000, 2001, 2002, 2004a, b; Chuo et al. 2002) claimed that the pre-earthquake anomalies in the ionospheric foF2 or GPSTEC appeared on 3 and 4 days before the Chi-Chi earthquake $\left(\mathrm{M}_{\mathrm{w}} 7.6, \mathrm{M}_{\mathrm{L}}\right.$ 7.3), and 1 and 3 days prior to the Chia-Yi earthquake $\left(M_{L} 6.4\right)$. However, these studies have not been crosschecked by simultaneous data sets observed at other places to confirm that the observed ionospheric anomalies were related to the earthquakes.

In this paper, we conduct a spatial analysis by crossexamining simultaneous data of $\mathrm{NmF} 2$ and GPS-TEC in Taiwan, Japan, and other places to find whether the anomalies observed in Taiwan during three periods of the Chi-Chi earthquake, the Chia-Yi earthquake, and between the two are local or global phenomena. The NmF2 and TEC are derived by local ionosondes and GPS receivers in Taiwan and Japan, while GPS-TEC at other places are retrieved from the global ionosphere maps (GIM) published by the Center for Orbit Determination in Europe (CODE; ftp://ftp.unibe.ch /aiub/CODE/).

\section{DATA ANALYSIS}

The $\mathrm{M}_{\mathrm{w}}$ 7.6 $\left(\mathrm{M}_{\mathrm{L}}\right.$ 7.3) Chi-Chi earthquake occurred at 0147 LT (120 EMT), 21 September 1999 (1747 UT, 20 September) in central Taiwan. This large earthquake results in surface ruptures extending over about $85 \mathrm{~km}$ along the Chelungpu fault with vertical thrust and left lateral strikeslip offsets (Ma et al. 2000). About a month later, at 1018 LT (120 EMT), 22 October 1999 (0218 UT, 22 October), the $\mathrm{M}_{\mathrm{L}} 6.4$ Chia-Yi earthquake occurred at about $55 \mathrm{~km}$ southwest of the epicenter of the Chi-Chi earthquake. The ChiChi earthquake is the largest event in Taiwan in the last cen- tury (Chang et al. 2000; Shin et al. 2000) and the Chia-Yi earthquake was another very large event that occurred soon after the Chi-Chi earthquake. The origin time, location, and magnitude of earthquakes in the Taiwan area during the study period can be retrieved from Central Weather Bureau Seismological Network (CWBSN).

To confirm the ionospheric anomalies being related to the two earthquakes as reported previously (Liu et al. 2000, 2001, 2004a; Chuo et al. 2001, 2002), we analyze the F2peak electron density $(\mathrm{NmF} 2)$ derived from the foF 2 not only at Chung-Li $\left(\mathrm{CHL} ; 25.0^{\circ} \mathrm{N}, 121.2^{\circ} \mathrm{E}\right)$ in Taiwan but also at Kokubunji (KKB; $\left.35.7^{\circ} \mathrm{N}, 139.5^{\circ} \mathrm{E}\right)$ in Japan (Fig. 1). Note that CHL is close to the two epicenters while KKB is far from them allowing for monitoring both inside and outside the two earthquake areas, respectively.

Taiwan is located in a seismically active zone of the rim encircling the Pacific Ocean and, therefore, earthquakes occur frequently. For instance, the recurrence interval of an $M \geq 5.0$ earthquake between 1991 and 1999 was about 13 - 15 days (Liu et al. 2004a). To minimize possible confounding effects of consecutive earthquakes and properly identify the abnormal signals, we computed the mean $\mathrm{NmF} 2$ $\left(\mathrm{NmF} 2_{\text {mean }}\right)$ values for the previous 15 days, and the associated standard deviation $(\sigma)$ as a reference at specific times. Then, we derived the normalized $\mathrm{NmF} 2(\mathrm{NmF} 2 *)$ values by the following equation:

$\mathrm{NmF}_{2} *(\mathrm{t})=\frac{\mathrm{NmF} 2(\mathrm{t})-\mathrm{NmF} 2_{\text {mean }}(\mathrm{t})}{\sigma(\mathrm{t})}$

The sampling interval at $\mathrm{CHL}$ is 15 and $60 \mathrm{~min}$. at KKB. If the $\mathrm{NmF} 2 *$ falls out of $-2 \sigma(\mathrm{t})$, we then declare that the abnormal signal is detected.

Meanwhile, by using the GAMIT software, widely adopted in geodesy and earth sciences, two co-located TECs derived from GPS receivers $\mathrm{S} 105\left(23.0^{\circ} \mathrm{N}, 121.1^{\circ} \mathrm{E}\right)$ in Taiwan and TSKB $\left(36.1^{\circ} \mathrm{N}, 140.1^{\circ} \mathrm{E}\right)$ in Japan (Fig. 1) are calculated. GAMIT is a comprehensive GPS analysis package developed at the Massachusetts Institute of Technology (MIT) and the Scripps Institution of Oceanography (SIO) for the estimation of three-dimensional relative positions of ground-based receivers and satellite orbits (King and Bock 2004). Note that the GPS-TEC derived by the GAMIT is considered as an observation without any further smoothing or interpretation process. Similar to Eq. (1), the normalized TEC (TEC*) is given as:

$\operatorname{TEC}^{*}(\mathrm{t})=\frac{\operatorname{TEC}(\mathrm{t})-\mathrm{TEC}_{\text {mean }}(\mathrm{t})}{\sigma(\mathrm{t})}$

where the TEC* is derived every $30 \mathrm{sec}$ and averaged every $15 \mathrm{~min}$. Moreover, for estimating the spatial extent of TEC 
anomalies in detail, we computed TEC data in the Okinawa-Kyushu area using GPS data observed by the GPS Earth Observation Network (GEONET) (Miyazaki et al. 1997). The Okinawa area is located at almost the same latitude as Taiwan, $24-27^{\circ} \mathrm{N}$ but slightly shifted in the longitude, $123-131^{\circ} \mathrm{E}$, while the Kyushu area is located in 27 $34^{\circ} \mathrm{N}$ and $129-132^{\circ} \mathrm{E}$.

To obtain GPS-TEC values at any location, the GIM is ideally used. The GIM is generated on a daily basis at CODE using data from GPS sites of the International GNSS Service (IGS) and other institutions. The vertical TEC is modeled in a solar-geomagnetic reference frame using a spherical harmonics expansion. In 1999, the degree and order of the spherical harmonics expansion were 12 and 8, respectively. Piece-wise linear functions are used for representation in the time domain. The spatial resolution is 2.5 -degree in latitude, and 5-degree in longitude and the temporal resolution is 2 hours. Schaer (1999) describes the computational algorithm in detail. For simplicity of cross comparison among the observations, we linearly interpolate yielding a 15 -minute resolution at a certain location. Remember that the GIM-TEC is obtained via the spherical harmonics expansion and the linear interpolation. Similarly, the normalized GIM-TEC (GIM-TEC*) can be given as:

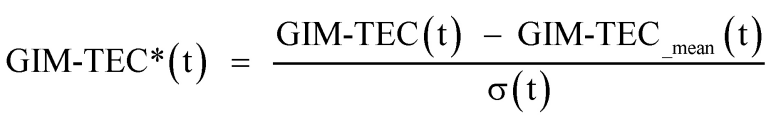

Taiwan is also right under the well-known equatorial ionization anomaly (EIA) (Ratcliffe 1972) region. To have a suitable cross comparison, GIM-TEC at four EIA regions, $\phi 30$ $\left(14.3^{\circ} \mathrm{N}, 30.0^{\circ} \mathrm{E}\right), \phi 120\left(22.1^{\circ} \mathrm{N}, 120.0^{\circ} \mathrm{E}\right), \phi 210\left(10.1^{\circ} \mathrm{N}\right.$, $\left.150.0^{\circ} \mathrm{W}\right)$, and $\phi 300\left(2.0^{\circ} \mathrm{N}, 60.0^{\circ} \mathrm{W}\right)$ have been isolated (Fig. 1). Note that the magnetic latitudes of these four EIA regions are $12.0^{\circ} \mathrm{N}$. In addition, we extract GIM-TEC* co-located at $\mathrm{CHL}$ and $\mathrm{KKB}$ (denoted, CHLg and KKBg) for further references. Table 1 summarizes locations of the ionosondes, the GPS receivers, and the GIM points in detail. Meanwhile, at low latitudes such as Taiwan, the ionospheric $\mathrm{NmF} 2$ and/or TEC also could be depressed about a few hours to 2 days after geomagnetic storm onsets (Kelley 1989; Davies 1990). To ensure that an observed NmF2 and/or TEC anomalous depression is earthquake related, we require that the reduction of the geomagnetic index Dst does not exceed -70 nT, otherwise it is considered to be geomagnetic storm related.

\section{RESULT AND INTERPRETATION}

Figure 2 displays that variations of $\mathrm{NmF} 2$ at $\mathrm{CHL}$ and

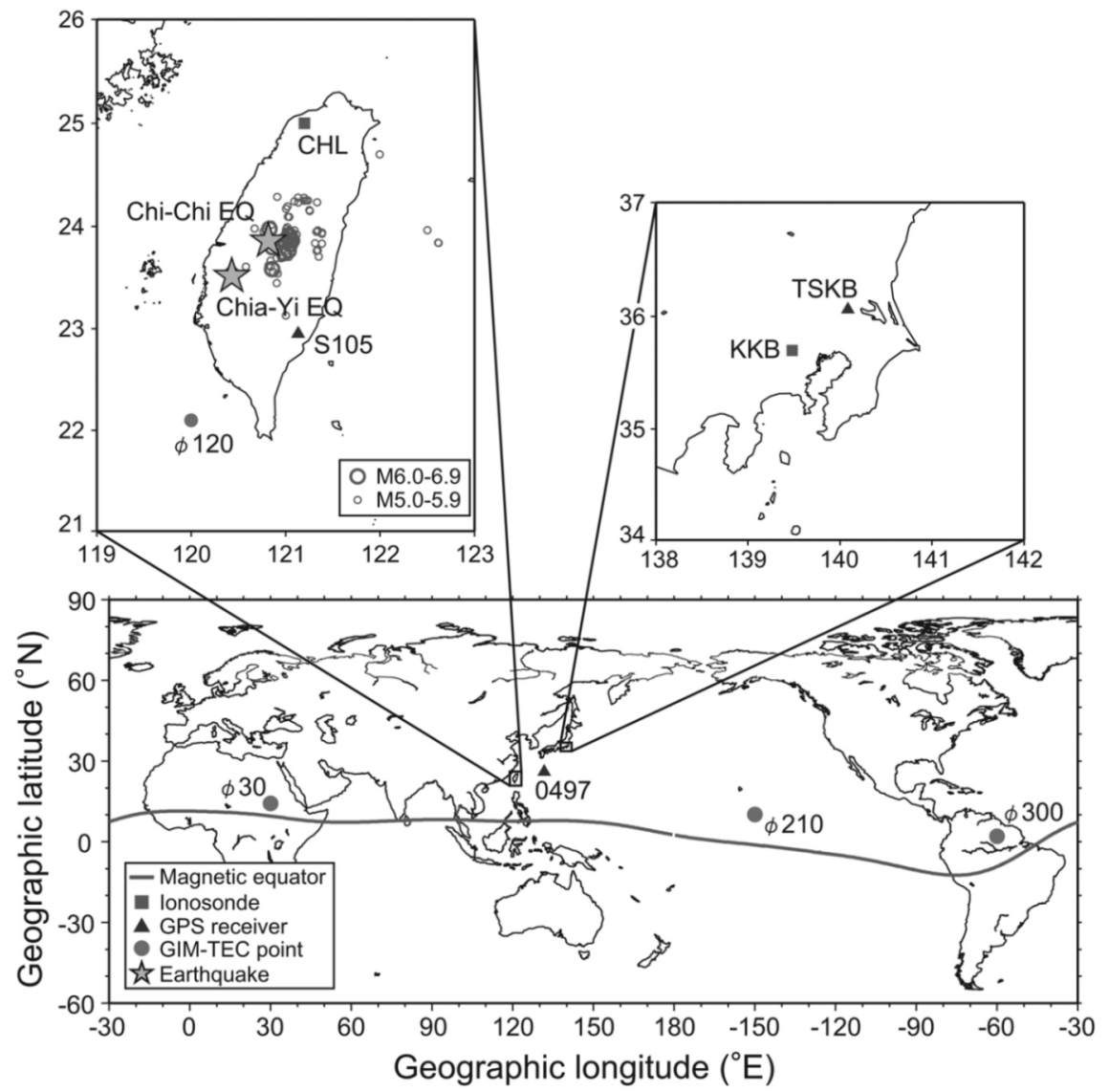

Fig. 1. Locations of ionosondes, GPS receivers, GIM-TEC points, and the epicenters of the Chi-Chi, Chia-Yi earthquakes, and M 5 - 6 earthquakes in Taiwan from 14 September to 28 October 1999. 
Table 1. Locations of ionosondes, GPS receivers, and GIM-TEC points.

\begin{tabular}{lccc}
\hline Station & Geographic latitude & Geographic longitude & Geomagnetic latitude \\
\hline Chung-Li (CHL) & $25.0^{\circ} \mathrm{N}$ & $121.2^{\circ} \mathrm{E}$ & $15.0^{\circ} \mathrm{N}$ \\
Kokubunji (KKB) & $35.7^{\circ} \mathrm{N}$ & $139.5^{\circ} \mathrm{E}$ & $26.8^{\circ} \mathrm{N}$ \\
S105 & $23.0^{\circ} \mathrm{N}$ & $121.1^{\circ} \mathrm{E}$ & $13.0^{\circ} \mathrm{N}$ \\
0497 & $25.8^{\circ} \mathrm{N}$ & $131.2^{\circ} \mathrm{E}$ & $16.3^{\circ} \mathrm{N}$ \\
TSKB & $36.1^{\circ} \mathrm{N}$ & $140.1^{\circ} \mathrm{E}$ & $27.2^{\circ} \mathrm{N}$ \\
$\phi 30$ & $14.3^{\circ} \mathrm{N}$ & $30.0^{\circ} \mathrm{E}$ & $12.0^{\circ} \mathrm{N}$ \\
$\phi 120$ & $22.1^{\circ} \mathrm{N}$ & $120.0^{\circ} \mathrm{E}$ & $12.0^{\circ} \mathrm{N}$ \\
$\phi 210$ & $10.1^{\circ} \mathrm{N}$ & $150.0^{\circ} \mathrm{W}$ & $12.0^{\circ} \mathrm{N}$ \\
$\phi 300$ & $2.0^{\circ} \mathrm{N}$ & $60.0^{\circ} \mathrm{W}$ & $12.0^{\circ} \mathrm{N}$ \\
\hline
\end{tabular}

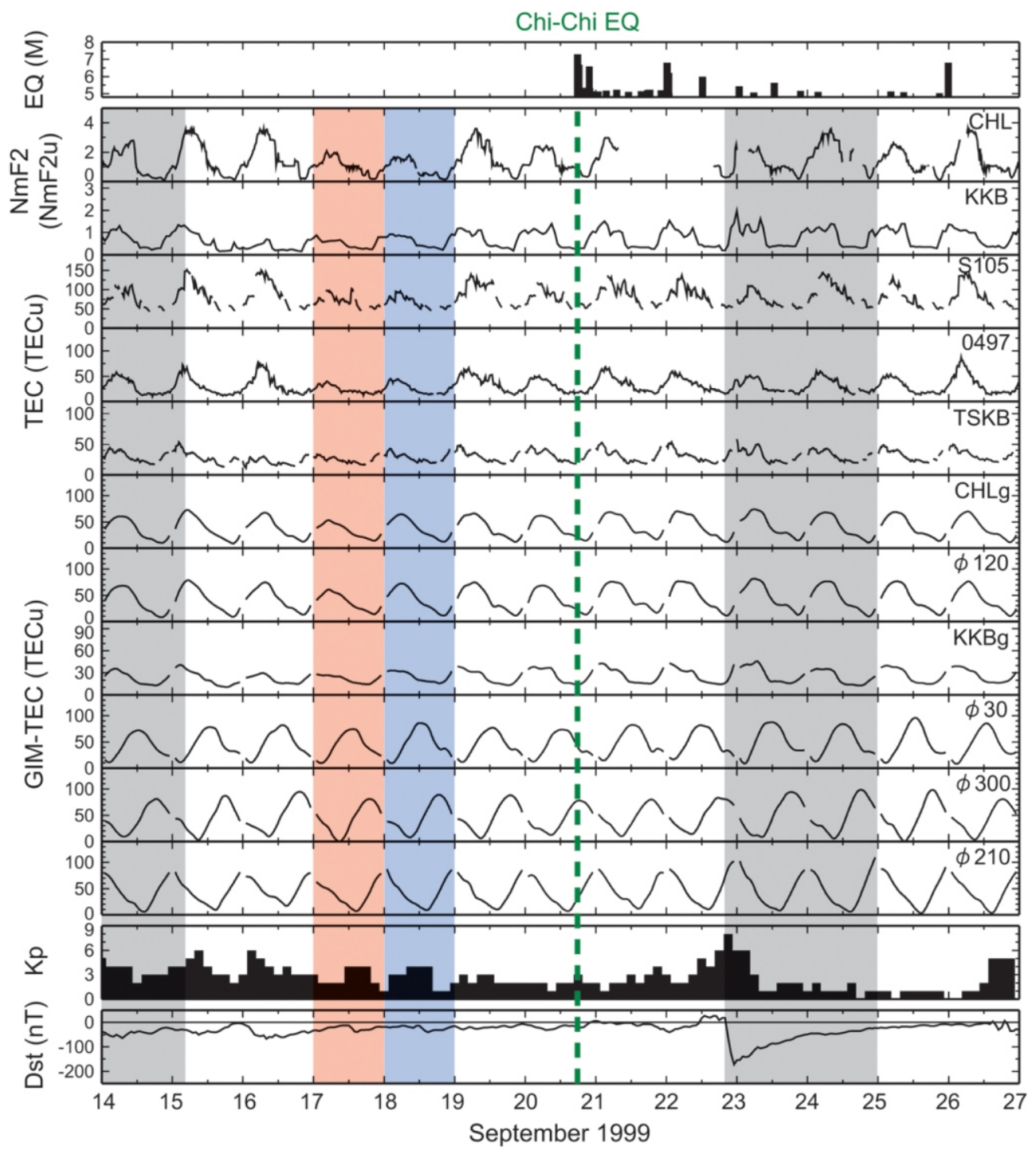

Fig. 2. The NmF2, TEC, GIM-TEC, Kp index, Dst index, and $M \geq 5.0$ seismic activity during the Chi-Chi earthquake period from 14 to 26 September 1999. The gray, red, and blue shaded regions denote the geomagnetic disturbed, global (possible magnetic storm), and anomaly features, respectively. 
TEC at S105 yield low values on 17 and 18 September, which are days 4 and 3 before the Chi-Chi earthquake. The variations of TEC at Minami-daitoh $\left(0497 ; 25.8^{\circ} \mathrm{N}, 131.2^{\circ} \mathrm{E}\right)$ in the Okinawa area show similar tendencies with S105. In order to detect anomalies, we calculated the running standard deviation $\sigma$ of the previous $1-15$ days and normalized the observed value on the 16th day. Figure 3 illustrates variations of the normalized quantities of $\mathrm{NmF}^{*}$, TEC*, and GIM-TEC* $*$ It may be seen that the $\mathrm{NmF}^{*}$ at $\mathrm{CHL}$ and TEC $^{*}$ at S105 exceed the lower threshold of $-2 \sigma$ on 17 and 18 September, which are $4-3$ days before the Chi-Chi earthquake. It is surprising to see that the GIM-TEC* at CHLg decreases, slightly exceeding $-2 \sigma$ on 17 September, but no clear reduction is observed on 18 September. By contrast, the $\mathrm{NmF}^{*}$ at $\mathrm{KKB}, \mathrm{TEC}^{*}$ at TSKB, and GIM-TEC* at $\mathrm{KKBg}$ decrease, exceeding the $-2 \sigma$ lower threshold on 15 and 16 September (days 6 and 5 before the earthquake). Although TEC* at TSKB and GIM-TEC* at KKBg decrease slightly exceeding $-2 \sigma$ on 17 September, no decrease feature is found on 18 September. Note that the NmF2* at KKB is about $-2 \sigma$ on 17 but not on 18 September. The TEC* at 0497 is about $-3 \sigma$ on 17 September. In general, the trends of GIM-TEC* are similar to those of TEC* and $\mathrm{NmF}^{*} *$ in Taiwan and in Japan. Moreover, GIM-TEC* at $\phi 30, \phi 120$, $\phi 210$, and $\phi 300$ decrease approaching $-2 \sigma$ on 17 and those on 18 September stay within $\pm 2 \sigma$ (within normal variation). This suggests a global effect appearing on 17 September. After the geomagnetic storm sudden commencement (SSC) on 22 September, the related reduction anomaly of TEC* at S105 is detected on 23 September. In this period, due to an electric power failure caused by the Chi-Chi earthquake, NmF2 was not constantly recorded at CHL.

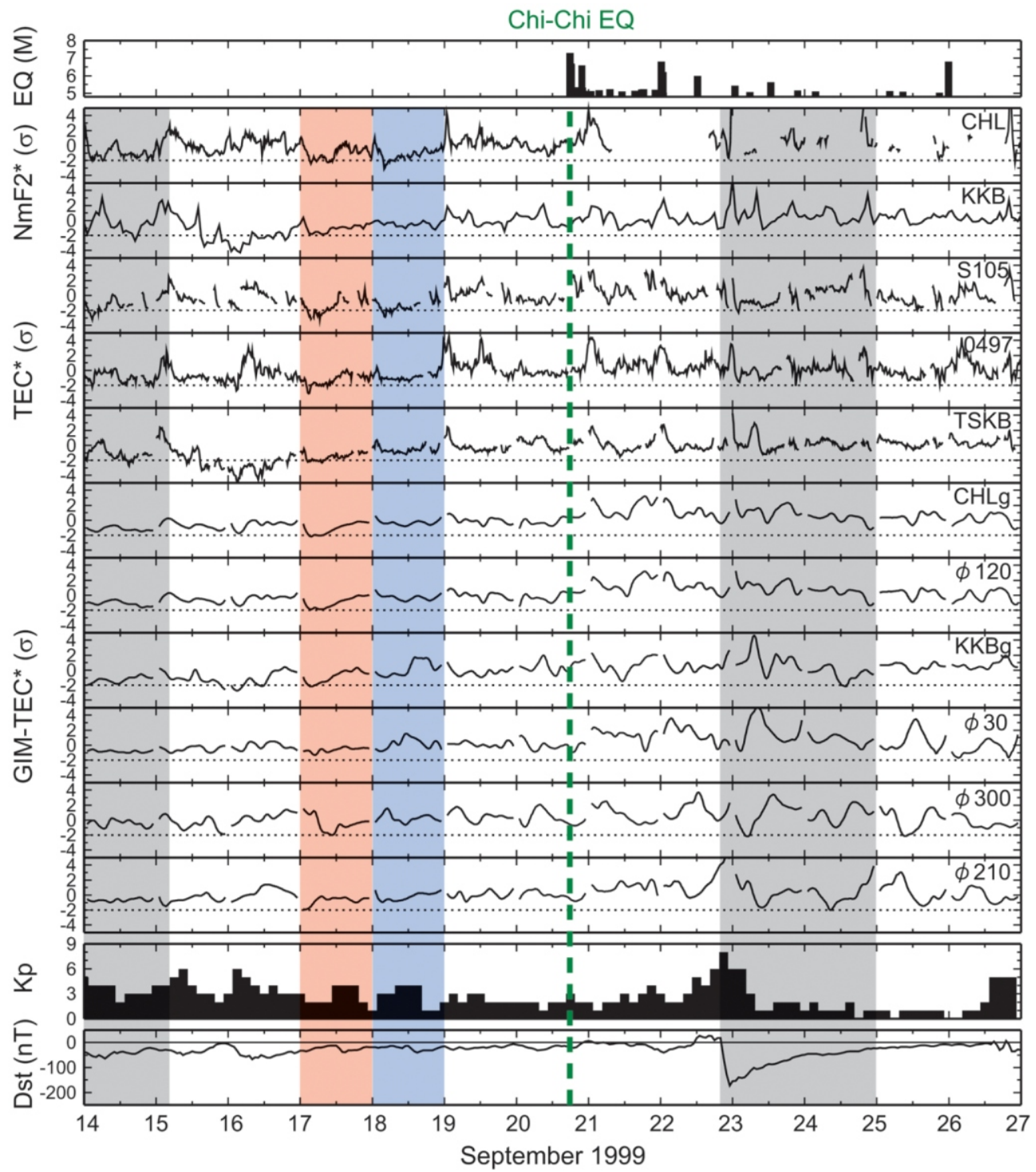

Fig. 3. The normalized quantities NmF2*, TEC*, and GIM-TEC*, as well as the geomagnetic Kp index, Dst index, and M $\geq 5.0$ seismic activity during the Chi-Chi earthquake period from 14 to 26 September 1999. 
Figures 4 and 5 reveal variations of the NmF2, TEC, GIM-TEC, Kp index, Dst index, and seismic activity as well as the associated normalized values during the period between the Chi-Chi earthquake and the Chia-Yi earthquake, from 27 September to 15 October, respectively. Again due to the power failure after the Chi-Chi earthquake, the CHL ionosonde yields many data gaps in the $\mathrm{NmF}^{*}$ data (Fig. 5). Notice that the value of TEC* at S105 decreased beyond $-2 \sigma$ on 1 October.

Variations of the NmF2, TEC, GIM-TEC, Kp index, Dst index, and the seismic activity from 16 to 28 October are illustrated in Fig. 6. The geomagnetic condition is relatively quiet until 21 October, which is one day before the Chia-Yi earthquake. In Fig. 6, it may be seen that the daily maximum values of $\mathrm{NmF} 2$ at $\mathrm{CHL}$ and TEC at $\mathrm{S} 105$ on 21 October are small in comparison with the other days. In fact, on 19 and 21 October, days 3 and 1 before the Chia-Yi earthquake, the $\mathrm{NmF}^{*}$ at $\mathrm{CHL}$ decreases exceeding the $-2 \sigma$ threshold (Fig. 7). However, the GIM-TEC* at CHLg does not show any anomalous behavior on those days. Moreover, the $\mathrm{NmF}^{*}$ at $\mathrm{KKB}$, the TEC* at TSKB and 0497, and the GIM-TEC* at KKBg do not decrease exceeding the $-2 \sigma$ threshold on 19 and 21 October either. Similarly, the GIM-TEC* values at $\phi 30, \phi 120, \phi 210$, and $\phi 300$ do not decrease exceeding $-2 \sigma$ on days 3 and 1 before the Chia-Yi earthquake. Although the causal relation is not understood, the GIM-TEC* at $\phi 300$ decreased significantly exceeding $-2 \sigma$ on 18 October.

Table 2 displays the correlation coefficients between TEC* computed by GAMIT and co-located NmF2* recorded by CHL ionosonde as well as TEC* and co-located GIM-TEC* in Taiwan and Japan during the three periods. For all three periods, the correlation coefficients between TEC* and $\mathrm{NmF}^{*}$ (or TEC* and GIM-TEC*) in Japan are

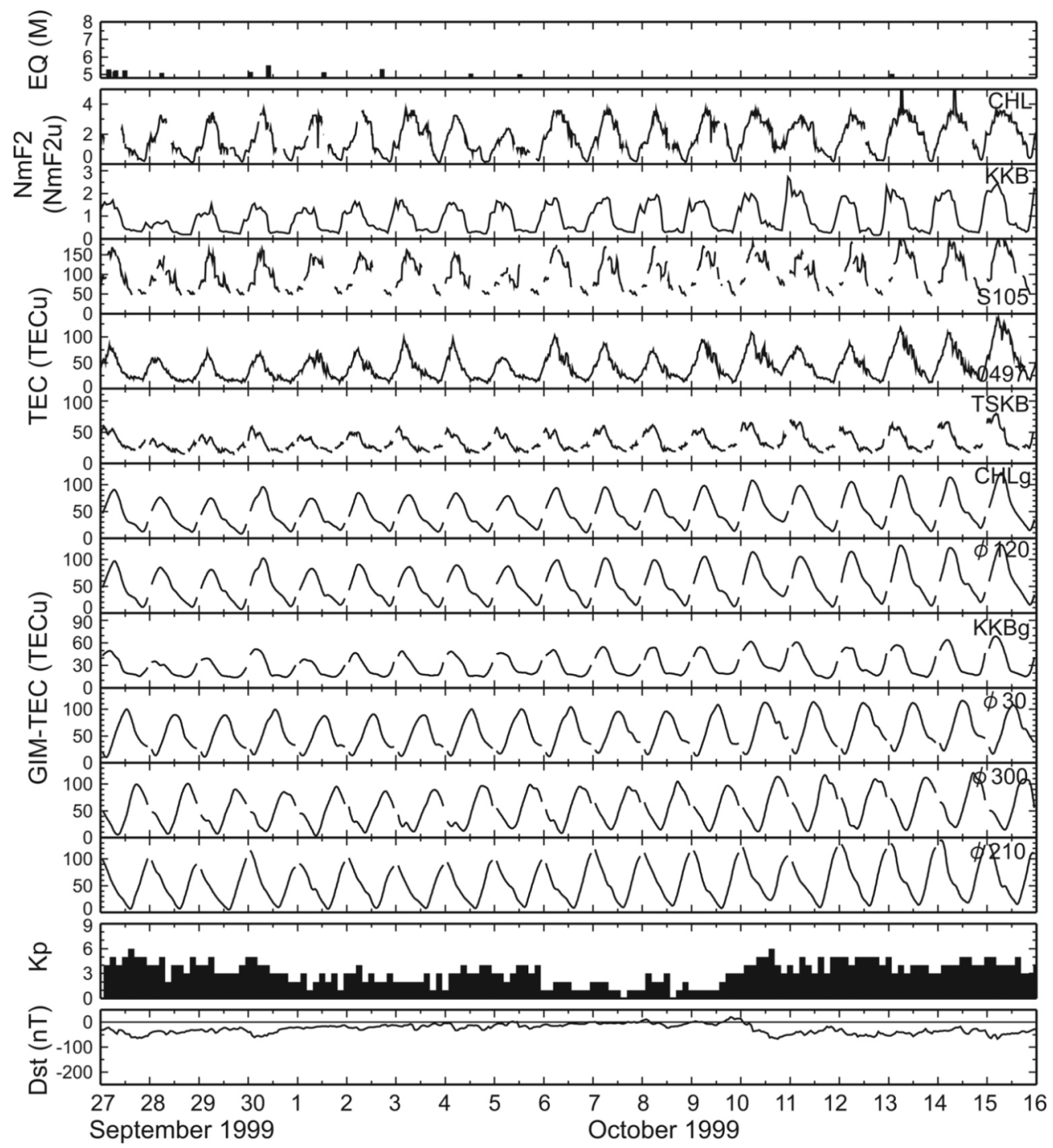

Fig. 4. The NmF2, TEC, GIM-TEC, Kp index, Dst index, and seismic activity of $M \geq 5.0$ earthquakes during the period between the Chi-Chi and Chia-Yi earthquakes from 27 September to 15 October 1999. 


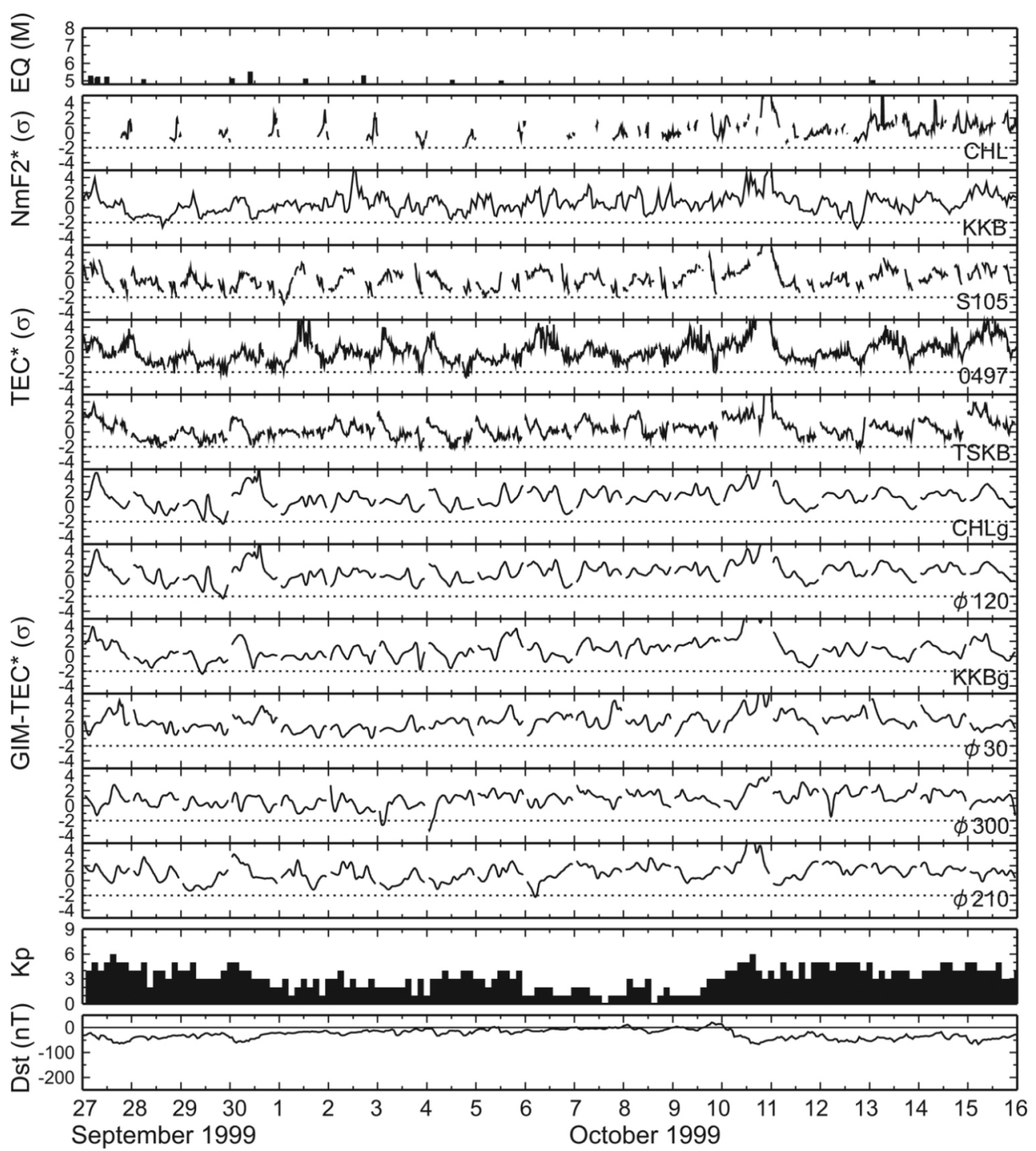

Fig. 5. The normalized quantities NmF2*, TEC*, and GIM-TEC*, as well as the geomagnetic Kp index, Dst index, and M $\geq 5.0$ seismic activity during the period between the Chi-Chi and Chia-Yi earthquakes from 27 September to 15 October 1999.

greater than those in Taiwan, respectively. In fact, each correlation coefficient between $\mathrm{TEC}^{*}$ and $\mathrm{NmF}^{*} *$ is greater than that between TEC* and GIM-TEC*, correspondingly. Meanwhile, it is interesting to find that the correlation coefficients between TEC* and GIM-TEC* yield the two smallest values during the Chi-Chi earthquake and the ChiaYi earthquake periods.

\section{DISCUSSION AND CONCLUSION}

Shiokawa et al. (2002) reported that three sequential magnetic storms onset at 0900 UT on 12 September, 2000 UT on 13 September, and 2200 UT on 14 September. Since ionospheric electron density might significantly decrease from a few hours to two days after a SSC or storm onset (Kelley 1989; Davies 1990), the decrease anomalies of TEC*, NmF2*, and GIM-TEC* observed in Japan on days 6 and 5 before the Chi-Chi earthquake (15 and 16 September) shown in Fig. 3 are most likely related to the reported storms. Following the three storms during 12 - 14 September, two geomagnetic SSCs occurred at 0753 and 2025 UT on 15 September (http://isgi.cetp.ipsl.fr/). Figure 3 reveals that all the observables, (except GIM-TEC* at $\phi 30$ ) significantly decrease on 17 September (day 4 before the Chi-Chi earthquake). TEC* values on 17 September of all stations in the OkinawaKyushu area also exceed $-2 \sigma$. These results strongly suggest that the decrease anomalies are related to the storm on 15 September. By contrast, the reduction anomalies appear only at CHL and S105 in the Taiwan area on 18 September, day 3 before the Chi-Chi earthquake. It is surprising to find that GIM-TEC* in Taiwan does not significantly decrease on the day. Recall that to construct a GIM, isolated ground-based 


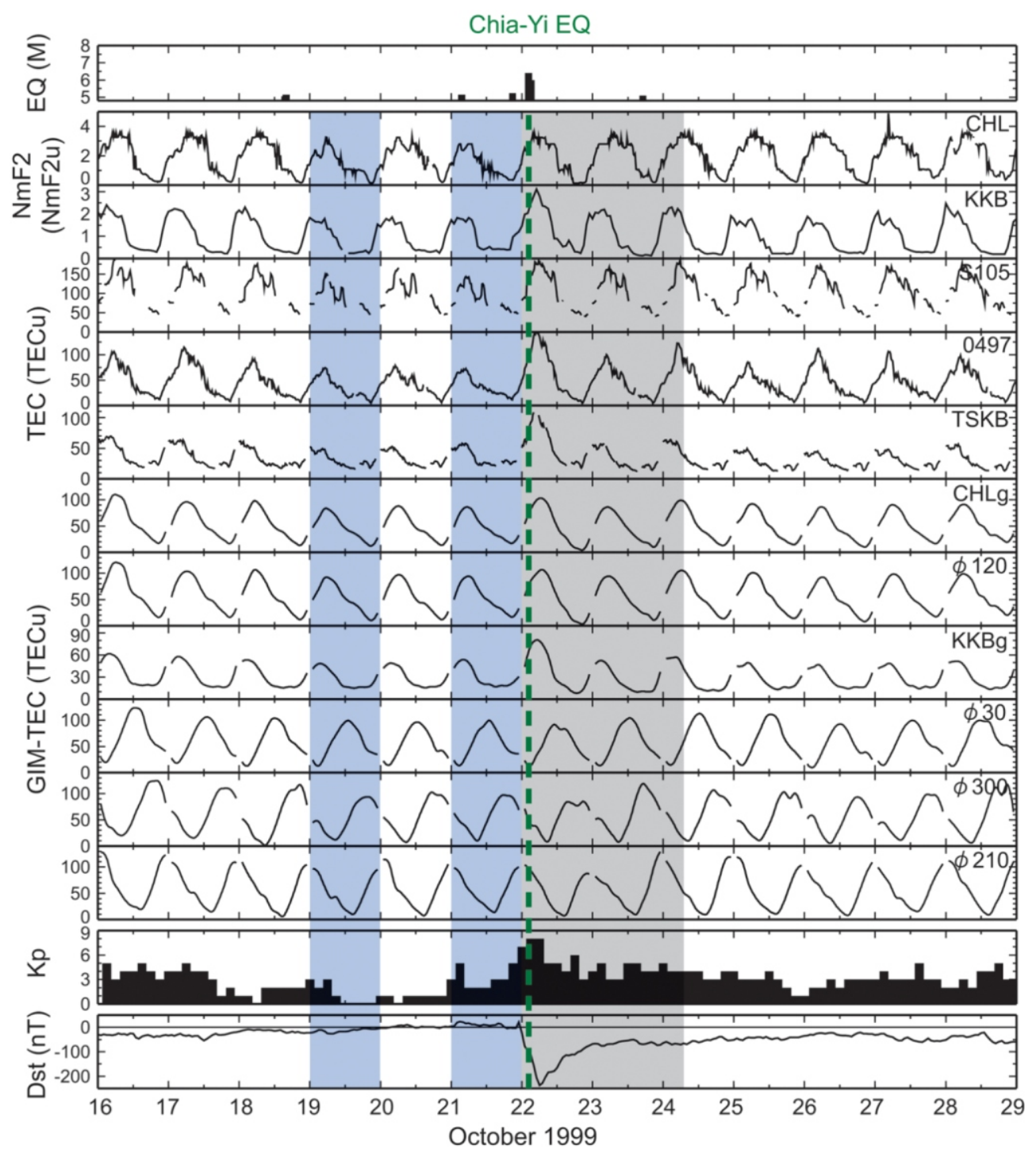

Fig. 6. The NmF2, TEC, GIM-TEC, Kp index, Dst index, and $M \geq 5.0$ seismic activity during the Chia-Yi earthquake period from 16 to 28 October 1999.

GPS receivers scattered worldwide are needed. The TECs derived from data recorded at the isolated receivers are further interpolated by means of the spherical harmonics to obtain the GIM. Therefore, in a place without isolated GPS receiver, the GIM-TEC is obtained by interpolation, which might introduce inaccuracy. The list (ftp://ftp.unibe.ch/aiub /CODE/1999/P1P29909_ALL.DCB.Z) in September 1999 shows that the isolated receivers near Taiwan are at PIMO $\left(14.6^{\circ} \mathrm{N}, 121.1^{\circ} \mathrm{E}\right)$, GUAM $\left(13.6^{\circ} \mathrm{N}, 144.9^{\circ} \mathrm{E}\right)$, WUHN $\left(30.5^{\circ} \mathrm{N}, 114.4^{\circ} \mathrm{E}\right), \mathrm{DAEJ}\left(36.4^{\circ} \mathrm{N}, 127.4^{\circ} \mathrm{E}\right)$, and TSKB, which, in fact, are all rather far from Taiwan. Nevertheless, significant reductions appeared in $\mathrm{NmF} 2 *$ at $\mathrm{CHL}$ and $\mathrm{TEC}^{*}$ at S105, inside Taiwan but not in TEC* at TSKB and 0497, GIM-TEC* at $\mathrm{KKBg}$, and $\mathrm{NmF2} *$ at $\mathrm{KKB}$. On the other hand, in the Okinawa-Kyushu area, TEC* at Haterumajima $\left(0751 ; 24.1^{\circ} \mathrm{N}, 123.8^{\circ} \mathrm{E}\right)$ exceeds the $-2 \sigma$ threshold. The
TEC* values at the other stations in the western Okinawa area also decrease to about $-2 \sigma$. This indicates that the anomalies on 18 September (day 3 before) may be associated with the Chi-Chi earthquake.

Figure 5 indicates that the TEC* decreased at S105 on 1 October. According to Liu et al. (2006), ionospheric electron density should significantly decrease within days $1-5$ before $M \geq 5.0$ earthquakes in Taiwan. Therefore the anomaly at S105 on 1 October is unlikely related to the Chia-Yi earthquake on 22 October 1999. However it is interesting to find that four moderate earthquakes, M 5.12, M 5.3, M 5.05, and M 5.01 occurred on 1,3,4, and 5 October 1999, which are 0 , 2, 3, and 4 days after the anomaly, respectively. Moreover, for these days, the decrease in TEC* at TSKB, NmF2* at $\mathrm{KKB}$, and GIM-TEC* at all observation points did not exceed the $-2 \sigma$ threshold. Since geomagnetic conditions are 


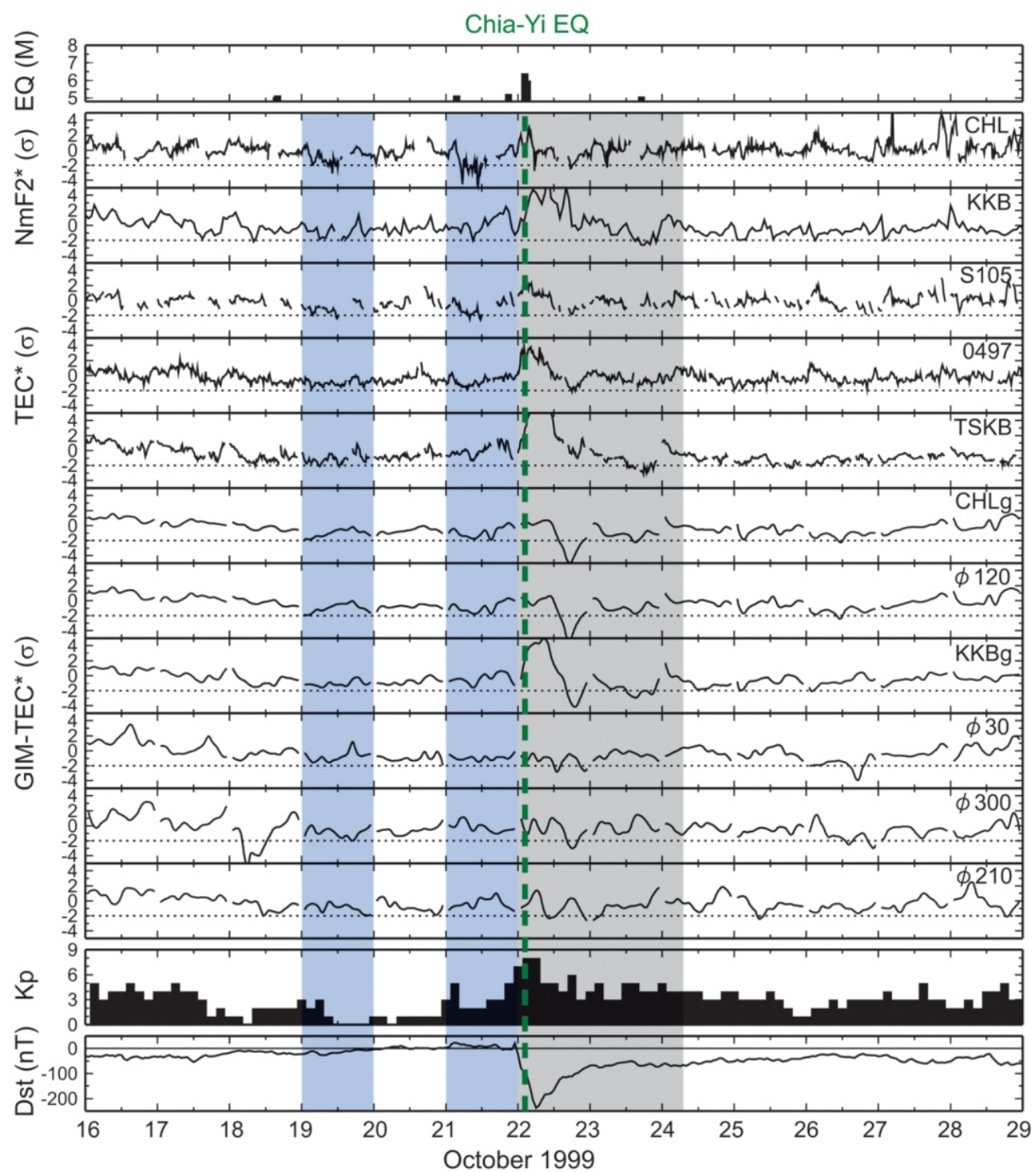

Fig. 7. The normalized quantities $\mathrm{NmF} 2 *$, TEC*, and GIM-TEC*, as well as the geomagnetic Kp index, Dst index, and M $\geq 5.0$ seismic activity during the Chia-Yi earthquake period from 16 October to 28 October 1999.

Table 2. The correlation coefficients between TEC* and NmF2*, TEC* and GIM-TEC*.

\begin{tabular}{lccccc}
\hline & \multicolumn{2}{c}{ TEC $^{*}-\mathbf{N m F 2}{ }^{*}$} & & \multicolumn{2}{c}{ TEC* - GIM-TEC* } \\
\cline { 2 - 3 } \cline { 5 - 6 } & $\begin{array}{c}\text { Taiwan } \\
\text { S105 - CHL }\end{array}$ & $\begin{array}{c}\text { Japan } \\
\text { TSKB - KKB }\end{array}$ & & $\begin{array}{c}\text { Taiwan } \\
\text { S105 - CHLg }\end{array}$ & $\begin{array}{c}\text { JSKBan } \\
\text { TSKKBg }\end{array}$ \\
\hline 14 - 26 September & 0.77 & 0.82 & & 0.45 & 0.72 \\
27 September - 15 October & 0.74 & 0.78 & & 0.63 & 0.74 \\
16 - 28 October & 0.67 & 0.81 & & 0.51 & 0.80 \\
\hline
\end{tabular}

relatively quiet during this period, the anomaly appearing on 1 October is a local phenomenon and possibly related to the four earthquakes.

During the Chia-Yi earthquake period, the reduction anomalies on 19 and 21 October are registered by $\mathrm{NmF} 2 *$ at CHL and TEC $^{*}$ at $\mathrm{S} 105$ and in the western Okinawa area, but not by $\mathrm{NmF}^{*}$ at $\mathrm{KKB}, \mathrm{TEC} *$ at TSKB nor in the eastern Okinawa and Kyushu area, nor for GIM-TEC* at six points 
(CHLg, KKBg, $\phi 30, \phi 120, \phi 210$, and $\phi 300$ ). Once again, no anomaly in the GIM-TEC* at $\phi 120$ might have resulted from the fact that no GPS receiver in Taiwan was included in the list of GPS receivers for the computation of the GIM in October 1999 (ftp://ftp.unibe.ch/aiub/CODE/1999/P1P29910 ALL.DCB.Z). Nevertheless, the spatial analysis indicates that the anomalies in Taiwan on days 3 and 1 before the Chia-Yi earthquake (19 and 21 October) are local phenomena around Taiwan.

The distance between Taiwan and Tokyo Japan is about $2200 \mathrm{~km}$. The anomalies of the Chi-Chi, Chia-Yi, and the M 5 earthquakes can only be observed in the Taiwan and western Okinawa area, which suggests that the extent of the reach of the disturbances due to these earthquakes is shorter than $2200 \mathrm{~km}$. Dobrovolsky et al. (1979) propose that the radius $R$ of earthquake preparation area, in which precursory signals are observed, can be given as $R=10^{0.43 \mathrm{M}}$, where $\mathrm{M}$ is the earthquake magnitude. For the largest event in this study, the Chi-Chi $\mathrm{M}_{\mathrm{w}} 7.6$ earthquake, we obtain $R=$ $1854 \mathrm{~km}$. Therefore, both the observation and theoretical estimation indicate that a spatial comparison of data simultaneously recorded at Taiwan and Tokyo may be used to identify ionospheric anomalies associated with Taiwan earthquakes.

Table 2 summarizes the correlations between the TEC*, the GIM-TEC*, and the NmF2*. It is found in comparison with Japan that there is a lack of good correlation between TEC* and GIM-TEC* in Taiwan during the periods of the Chi-Chi and the Chia-Yi earthquakes. The poor correlation is certainly because there were no GPS stations in the Taiwan area for constructing the GIM in 1999. However, the correlation should become even worse, when the anomalies also appear during the two earthquake periods. In fact, the poor correlation of Taiwan in Table 2 vice versa suggests that the ionosphere was highly disturbed prior to the 1999 Chi-Chi and Chia-Yi earthquakes and that such disturbances were local phenomena.

The spatial analysis in this study indicates that the reduction anomalies on day 3 before the Chi-Chi earthquake, and days 3 and 1 before the Chia-Yi earthquake may be seismically related. This finding is in agreement with the results reported by Liu et al. (2000, 2001, 2004a) and Chuo et al. (2001, 2002). The spatial extents of these anomalies did not reach to the mid-latitude (i.e., the Tokyo and Kyushu area), appeared only in the Taiwan and western Okinawa area in the EIA region. This result supports that the EIA crest moves equatorward as reported by Liu et al. (2001). On the other hand, the significant NmF2 and TEC reductions on 17 September (4 days before the Chi-Chi earthquake) appeared not only inside the Taiwan and western Okinawa area but also outside (i.e., the eastern Okinawa, Kyushu, and Tokyo area), indicating that the reduction anomalies were possibly affected by a geomagnetic storm on 15 September (i.e., global effect or non-earthquake related). In conclusion, this study shows that spatial analysis could be useful in identifying earthquake related anomalies.

Acknowledgements The authors wish to thank Koichi C. H. Chen in Institute of Space Science, National Central University for supporting this work and Prof. W. M. Boerner of the University of Illinois at Chicago for useful comments. The GPS data at S105 were obtained from the Ministry of Interior of Taiwan, the GPS data at TSKB were obtained from the "Scripps Orbit and Permanent Array Center" (SOPAC), and GEONET GPS data were provided by the Geographical Survey Institute of Japan. The NmF2 datasets at CHL were retrieved from the Chung-Li ionospheric observatory and the $\mathrm{NmF} 2$ data at KKB were provided by WDC for Ionosphere, Tokyo, National Institute of Information and Communications Technology. The GIM data were isolated from the Center for Orbit Determination in Europe (CODE). The Dst index and the Kp index were provided by world data center (WDC) for Geomagnetism, Kyoto. This research has partly been supported by a Grantin-Aid for Scientific Research of the Japan Society for the Promotion of Science (JSPS) (16560360) and by the Japan-Taiwan Joint Research Program of the Interchange Association, Japan.

\section{REFERENCES}

Birfeld, Y. G., 1974: Seismo-ionospheric coupling. Application to ionospheric earthquake prediction. In: Osimi, M. (Ed.), Search for Earthquake Precursors at Prognostic Networks, Nauka, Moscow, 200-202.

Calais, E. and S. Amarjargal, 2000: New constraints on current deformation in Asia from continuous GPS measurements at Ulan Baatar, Mongolia. Geophys. Res. Lett., 27, 15271530, doi: 10.1029/1999GL005444. [Link]

Chang, C. H., Y. M. Wu, T. C. Shin, and C. Y. Wang, 2000: Relocation of the 1999 Chi-Chi earthquake in Taiwan. Terr. Atmos. Ocean. Sci., 11, 581-590.

Chen, Y. I., J. Y. Liu, Y. B. Tsai, and C. S. Chen, 2004: Statistical tests for pre-earthquake ionospheric anomaly. Terr. Atmos. Ocean. Sci., 15, 385-396.

Chuo, Y. J., Y. I. Chen, J. Y. Liu, and S. A. Pulinets, 2001: Ionospheric fo $F 2$ variations prior to strong earthquakes in Taiwan area. Adv. Space Res., 27, 1305-1310, doi: 10.1016/ S0273-1177(01)00209-5. [Link]

Chuo, Y. J., J. Y. Liu, S. A. Pulinets, and Y. I. Chen, 2002: The ionospheric perturbations prior to the Chi-Chi and Chia-Yi earthquakes. J. Geodyn., 33, 509-517, doi: 10.1016/ S0264-3707(02)00011-X. [Link]

Datchenko, E. A., V. I. Ulomov, and C. P. Chernyshova, 1972: Electron density anomalies as the possible precursor of Tashkent earthquake. Dokl. Uzbek. Acad. Sci., 12, 30-32.

Davies, K., 1990: Ionospheric Radio, Peter Peregrinus Ltd., London, $580 \mathrm{pp}$.

Dobrovolsky, I. P., S. I. Zubkov, and V. I. Miachkin, 1979: Esti- 
mation of the size of earthquake preparation zones. Pure Appl. Geophys., 117, 1025-1044, doi: 10.1007/BF0087 6083. [Link]

Gokhberg, M. B., A. V. Ustov, V. A. Liperovaskiy, R. K. H. Liperovskaya, E. P. Kharin, and S. L. Shalimov, 1989: Perturbations of the ionospheric F-layer prior to strong earthquakes. Izvestiya, Earth Phys., 24, 254-260.

Hayakawa, M. (Ed.), 1999: Atmospheric and Ionospheric Electromagnetic Phenomena with Earthquakes, Terra Sci. Pub. Co., Tokyo, 996 pp.

Hayakawa, M. and Y. Fujinawa (Eds.), 1994: Electromagnetic Phenomena Related to Earthquake Predication, Terra Sci. Pub. Co., Tokyo, 667 pp.

Hayakawa, M. and O. A. Molchanov (Eds.), 2002: Seismo Electromagnetics: Lithosphere-Atmosphere-Ionosphere Coupling, TERRAPUB, Tokyo, 477 pp.

Hunscucker, R. D., 1991: Radio Techniques for Probing the Terrestrial Ionosphere, Springer, Berlin, Germany.

Kelley, M. C., 1989: The Earth's Ionosphere, Academic Press, San Diego, $487 \mathrm{pp}$

King, R. W. and Y. Bock, 2004: Documentation for the GAMIT GPS Analysis Software, Release 10.2, Massachusetts Institute of Technology and University of California at San Diego, Cambridge.

Leick, A., 1995: GPS Satellite Surveying, John Wiley, New York, $560 \mathrm{pp}$.

Liu, J. Y., H. F. Tsai, and T. K. Jung, 1996: Total electron content obtained by using the global positioning system. Terr. Atmos. Ocean. Sci., 7, 107-117.

Liu, J. Y., Y. I. Chen, S. A. Pulinets, Y. B. Tsai, and Y. J. Chuo, 2000: Seismo-ionospheric signatures prior to $M \geq 6.0$ Taiwan earthquakes. Geophys. Res. Lett., 27, 3113-3116, doi: 10.1029/2000GL011395. [Link]

Liu, J. Y., Y. I. Chen, Y. J. Chuo, and H. F. Tsai, 2001: Variations of ionospheric total electron content during the Chi-Chi earthquake. Geophys. Res. Lett., 28, 1383-1386, doi: 10.1029/2000GL012511. [Link]

Liu, J. Y., Y. J. Chuo, S. A. Pulinets, H. F. Tsai, and X. Zeng, 2002: A study on the TEC perturbations prior to the Rei-Li, Chi-Chi and Chia-Yi earthquakes. In: Hayakawa, M. and O. A. Molchanov (Eds.), Seismo Electromagnetics: Lithosphere-Atmosphere-Ionosphere Coupling, TERRAPUB, Tokyo, 297-301.

Liu, J. Y., Y. J. Chuo, S. J. Shan, Y. B. Tsai, Y. I. Chen, S. A. Pulinets, and S. B. Yu, 2004a: Pre-earthquake ionospheric anomalies registered by continuous GPS TEC measurements. Ann. Geophys., 22, 1585-1593.

Liu, J. Y., Y. I. Chen, H. K. Jhuang, and Y. H. Lin, 2004b: Iono- spheric foF2 and TEC anomalous days associated with M $\geq 5.0$ earthquakes in Taiwan during 1997-1999. Terr. Atmos. Ocean. Sci., 15, 371-383.

Liu, J. Y., Y. I. Chen, Y. J. Chuo, and C. S. Chen, 2006: A statistical investigation of pre-earthquake ionospheric anomaly. J. Geophys. Res., 111, A05304, doi: 10.1029/2005JA 011333. [Link]

Ma, K. F., T. R. A. Song, S. J. Lee, and H. I. Wu, 2000: Spatial slip distribution of the September 20, 1999, Chi-Chi, Taiwan, earthquake $\left(\mathrm{M}_{\mathrm{W}} 7.6\right)$ - inverted from teleseismic data. Geophys. Res. Lett., 27, 3417-3420, doi: 10.1029/2000 GL011393. [Link]

Miyazaki, S., T. Saito, M. Sasaki, Y. Hatanaka, and Y. Iimura, 1997: Expansion of GSI's nationwide GPS array. Bull. Geogr. Surv. Inst., 43, 23-34.

Nestorov, G. T., 1979: A possible ionospheric presage of the Vrancha earthquake of March 4, 1977. Doklady (Transactions) Bulgarian Acad. Sci., 32, 443-446.

Pulinets, S. A., 1998: Seismic activity as a source of the ionospheric variability. Adv. Space Res., 22, 903-906, doi: 10.1016/S0273-1177(98)00121-5. [Link]

Pulinets, S. A. and K. A. Boyarchuk, 2004: Ionospheric Precursors of Earthquakes, Springer, Berlin, Germany, 316 pp.

Pulinets, S. A., A. D. Legen'ka, and V. A. Alekseev, 1994: Preearthquake ionospheric effects and their possible mechanisms. In: Kikuchi, H. (Ed.), Dusty and Dirty Plasmas, Noise, and Chaos in Space and in the Laboratory, Plenum Publishing, New York, 545-557.

Ratcliffe, J. A., 1972: An Introduction to the Ionosphere and Magnetosphere, Cambridge University Press, London.

Sardon, E., A. Rius, and N. Zarraoa, 1994: Estimation of the transmitter and receiver differential biases and the ionospheric total electron content from global positioning system observations. Radio Sci., 29, 577-586, doi: 10.1029/ 94RS00449. [Link]

Schaer, S., 1999: Mapping and predicting the Earth's ionosphere using the Global Positioning System. Ph.D. Thesis, Astronomical Institute, University of Bern, Bern, Switzerland.

Shin, T. C., K. W. Kuo, W. H. K. Lee, T. L. Teng, and Y. B. Tsai, 2000: A preliminary report on the 1999 Chi-Chi (Taiwan) earthquake. Seismol. Res. Lett., 71, 24-30.

Shiokawa, K., Y. Otsuka, T. Ogawa, N. Balan, K. Igarashi, A. J. Ridley, D. J. Knipp, A. Saito, and K. Yumoto, 2002: A large-scale traveling ionospheric disturbance during the magnetic storm of 15 September 1999. J. Geophys. Res., 107, 1088, doi: 10.1029/2001JA000245. [Link] 